\title{
Manuel Julián Grajales. Propagador de la vacuna antivariólica en América del Sur. Anatomista y cirujano
}

\author{
Enrique Laval
}

\section{Manuel Julian Grajales. Propagator of smallpox vaccine in South America. Anatomist and surgeon.}

Grajales came to Chile in December 1807, noting that since 1805 smallpox vaccination had been introduced by Fray Pedro Manuel Chaparro, supported by the Councilor Nicholas Matorras. He founded the Vaccination Boards of Valparaiso and Santiago in 1808 and became professor of anatomy and surgery in 1819. In 1823 he received his authorization to practice medicine. He wanted to finish his medical studies at the University of San Marcos in Lima, but the war of Independence made this impossible. He returned to Spain in 1825. In 1848, he became Member of Honor of the Faculty of Medicine, Universidad de Chile.

Key words: Smallpox vaccine; anatomist; surgeon; member of honor of the Faculty of Medicine, Universidad de Chile.

Palabras clave: Vacuna antivariólica; anatomista; cirujano; miembro honorario de la Facultad de Medicina de la Universidad de Chile.

\section{Introducción}

$\mathrm{E}$ 1 doctor Sergio De Tezanos Pinto, en su "Breve Historia de la Medicina en Chile" (1995), al referirse a don Manuel Julián Grajales, dice que "era un personaje curioso de nuestro país", a quien Pedro Lautaro Ferrer lo llama Don y el doctor Enrique Laval Manrique no lo incluye en su obra "Noticias sobre los médicos en Chile" pese a pertenecer al siglo XIX. Estos hechos se deben, apunta De Tezanos Pinto a que Grajales no era médico y, sin embargo, jugó un importante papel en la medicina chilena, donde llegó a ostentar, si no grandes grados académicos, al menos una participación en actividades universitarias de alto nivel. No incluir su nombre nos ha parecido "un poco ingrato" y su actuar nos permite dimensionar la magnitud de la viruela en nuestra medicina ${ }^{1,2}$.

El doctor Enrique Laval Manrique falleció el 25 de mayo de 1970. Sus "Noticias sobre los médicos en Chile" publicadas en 1972, sólo alcanzaron a incluir los profesionales cuyos apellidos comienzan con las letras C - D y E, del siglo XIX. Como legatario de mi padre, se encuentran en poder mío, las restantes biografías dactilografiadas de los médicos chilenos y extranjeros que ejercieron durante aquel siglo en el país. Naturalmente entre ellas está la de don Manuel Julián Grajales. Si mi padre hubiera estado vivo cuando el profesor De Tezanos Pinto escribió lo transcrito al principio, con toda seguridad se habría puesto en contacto con él, a quien admiraba por sus trabajos de

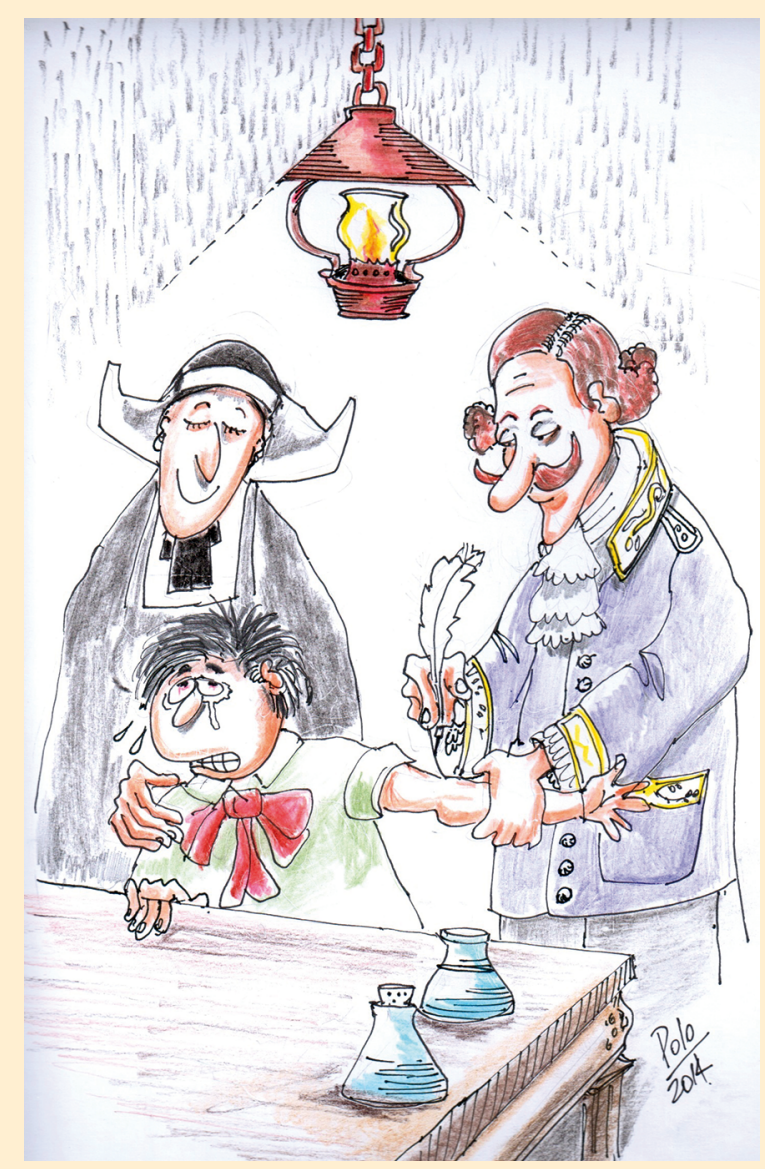

Pontificia Universidad Católica de Chile.

Facultad de Medicina

Programa de Estudios Médicos

Humanísticos.

Recibido: 20 de octubre de 2014

Correspondencia a:

Enrique Laval

revinf@sochinf.cl 
investigación y pasión por la historia de la medicina, para explicarle lo señalado. El insigne catedrático porteño, falleció el 30 de mayo de 2007, honrando con su quehacer, la medicina de Valparaíso.

En todo caso, considero importante agregar que en Anales Chilenos de la Historia de la Medicina, Vol. 9-10, 1967-68, el doctor Laval Manrique, escribió latamente sobre la importancia de don Manuel Julián Grajales en relación con la vacunación antivariólica en Chile.

\section{Grajales propagador de la vacuna antivariólica y su actividad en Chile}

Laval Manrique ${ }^{3}$, en el texto sobre don Manuel Julián Grajales, expone que llegó a Chile en diciembre de 1807, "sin haber terminado sus estudios médicos en España", siendo designado ayudante de la expedición, destinada por la Metrópoli a propagar la vacuna antivariólica en América, la que partió de La Coruña el 30 de noviembre de 1803, a cargo del médico don Francisco Javier Balmis. La expedición se dividió en dos cuerpos en Caracas, uno al mando de Balmis para difundir la vacuna en Méjico y América Central y otro a cargo de Francisco Salvany destinado a vacunar en América meridional. Grajales fue nombrado ayudante de Salvany y en cumplimiento de su misión llegó a Chile, en 1807.

Grajales estudio en el Colegio de Cirugía de San Carlos de Madrid, fundado por Carlos III. A su llegada a Chile supo que la vacuna fue introducida dos años antes por fray Pedro Manuel Chaparro, el que ayudado por el Regidor Nicolás Matorras, habían ya practicado casi ocho mil vacunaciones. El fluido vacunífero fue enviado a Chile por el Marqués de Sobremonte, virrey del Plata, quien lo había recibido del Brasil, por intermedio de una expedición lusitana, en enero de 1805.

En Chile la primera vacunación tuvo lugar el día 8 de octubre de 1805, practicada por fray Chaparro en la puerta del Cabildo Metropolitano².

Inició Grajales sus trabajos en Valparaíso y el 21 de enero de 1808 constituyó la Junta de Vacuna del Puerto, recorriendo luego Quillota, Aconcagua, Casablanca y Melipilla, llegando a Santiago en abril de ese año. El 18 de octubre de 1808 quedó establecida la Junta Central de Vacuna de la capital. Ejerció su labor profesional en Santiago, destacándose por su destreza quirúrgica, abnegación y sencillez. En 1812 volvió al Perú con el fin de terminar sus estudios en la Universidad de San Marcos, pero los acontecimientos de la Independencia, obligaron al Virrey Abascal a embarcarlo como cirujano en la fragata Thomas, la que fue apresada el 7 de junio de 1813 en Talcahuano y hecho prisionero, prestó sus servicios a los patriotas.

Producida la independencia de Chile, el Instituto Nacional fue restablecido por el Senado el 12 de noviembre de 1818 y reinaugurado en julio de 1819. Don José Ignacio
Cifuentes quedó encargado aquel año de organizar el cuerpo directivo y docente del plantel, proponiendo a don Manuel Julián Grajales como profesor de anatomía y cirugía; al doctor Eusebio Oliva, catedrático de Prima y de Medicina teórica. O'Higgins aceptó y extendió sus nombramientos.

Los cursos de medicina no funcionaron por falta de alumnos: no obstante, interesa recordar que Grajales el 7 de agosto de 1819 presentó al Senado un plan de estudios médicos-quirúrgicos donde expresaba que "para formar algunos discípulos que aprovecharan el tiempo y las lecciones es necesario que se hagan en el Hospital Militar, pues aquí hay extensión y cadáveres para las lecciones de anatomía, que es la base fundamental de la medicina, pues sin ella no se puede dar un perfecto médico ni cirujano..."

El doctor Nataniel Cox combatió con vehemencia el plan de Grajales, en informe presentado al Senado el 4 de octubre de $1819^{5}$.

\section{Grajales anatomista y cirujano. Autorización para ejercer la profesión}

Como se ha visto, Grajales fue nombrado profesor de anatomía y cirugía del Instituto Nacional en 1819. El 3 de mayo de ese mismo año recibió la designación de examinador de flebotomía y fiscal del Protomedicato.

El 14 de mayo de 1823 fue admitido legalmente al ejercicio profesional por resolución del Protomedicato.

Con motivo de la guerra de la independencia y sus secuelas, se organizó el Hospital Militar de Santiago (que funcionó en el antiguo edificio del Hospital San Francisco de Borja) y Grajales fue su cirujano hasta 1825 , fecha de su regreso a España.

¿Qué lo indujo a volver a su patria en ese año? No se sabe, pero de un oficio relacionado con conexión inmediata con la anatomía se desprendería que en enero de ese año, no abrigaba ningún propósito de abandonar el país.

Dice Grajales el 22 de enero de 1825: "Sin anatomía no hay medicina ya que sin conocer el cuerpo sobre el que se obra es imposible hacer aplicaciones acertadas; así por defecto de aquellos conocimientos ha ocurrido mala suerte con la facultad médica en Chile: se han perpetuado enfermedades crónicas porque sin disección no han podido los médicos conocer las partes que afectan para subir a sus causas: se presentan nuevas que no estando en las catálogos del empirismo, llevan millares de víctimas a la tumba, hasta que la casualidad tropieza con el especifico. En fin Excmo. Señor, se procede a ciegas y la consecuencia es la despoblación del país más sano, de mejor clima y alimentos. Ud. lo toca en las razones estadísticas y basta ver la estancación del censo de un país, que para todos los cálculos debía doblar a los veinte años.

Convencido de estas tristes verdades, me he empeñado 
en practicar y generalizar los conocimientos anatómicos; apenas hay un día que no haga una o muchas disecciones; pero lo más triste es hacerlas a descubierto sobre las miasmas de los sepulcros, tostado del sol en verano o por sobre el barro en el invierno; no hay anfiteatro como exige la salud pública, la educación de los jóvenes y la decencia, siendo fácil erigirlo en el Panteón, sin otro gasto que el de una pieza de diez varas con su mesón al medio y estantes ordinarios a los costados: allí mismo se hace y aun está trabajando el material; es un departamento especial de estas cosas; porque debiendo alejar los contagios deben centralizar las disecciones que o desparramadas o hechas dentro de la población, frustran su objeto: es de interés de la población, que es del primero del Estado y eso lo tiene dispuesto toda la ley que se hace en los países cultos; por lo que no dudo que la justificación bienhechora de V.E. lo mandará construir y que hecho se ponga a mi disposición". Manuel Grajales ${ }^{6}$.

La obra según informe del Administrador del Panteón, costaría 500 pesos y Grajales concurriría con el valor del terreno.

Grajales tuvo gran interés por la anatomía y practicaba sus disecciones en el Panteón y en el Hospital Militar. En "El Censor de la Revolución" de 30 de abril de 1820, dio a conocer el resultado de una autopsia que había practicado en 1819 en el Hospital de Mujeres de Santiago: se trataba de una muchacha de 22 años que había padecido durante largo tiempo de una diarrea continua y en el ovario izquierdo se encontró un tumor esférico del tamaño de un huevo de avestruz: era un quiste dermoideo. Parece que esta autopsia es una de las primeras - no se dice realizadaen el país, sino publicada.

El 5 de octubre de 1848 la Facultad de Medicina de la Universidad de Chile, confirió a Manuel Julián Grajales, el título de Miembro Honorario, enviándole a España el documento pertinente. Grajales falleció en su patria en 1855 , a edad avanzada ${ }^{3}$.

\section{Resumen}

Grajales llegó a Chile en diciembre de 1807, comprobando que desde 1805 se vacunaba contra la viruela por fray Pedro Manuel Chaparro, secundado por el Regidor Nicolás Matorras. Creó las Juntas de Vacuna de Valparaíso y Santiago en 1808, nombrado profesor de anatomía y cirugía en 1819. Admitido al ejercicio profesional por resolución del Protomedicato en 1823. Quiso terminar sus estudios médicos en la Universidad de San Marcos de Lima, pero por razones de la guerra de la Independencia no le fue posible. Volvió a España en 1825. En 1848 recibió el diploma de Miembro Honorario de la Facultad de Medicina de la Universidad de Chile.

\section{Referencias bibliográficas}

1.- De Tezanos Pinto S. Breve Historia de la Medicina en Chile. Ed. Universidad de Valparaíso. 1995. Chile.

2.- Ferrer P L. Historia General de la Medicina en Chile. Impta. Talca. Talca. Chile, 1904.

3.- Laval M E. Desarrollo de la viruela en Chile, desde la Conquista hasta 1825.- Grajales.- An Chil Hist Med 1967-68; 9-10: 241-76.

4.- Sesiones de los Cuerpos Legislativos. Tomo III. P.154. Sin año de fecha.

5.- $\quad$ Cox N. Informe presentado al Senado el 4 de julio de 1816. Sesiones de los Cuerpos Legislativos. Tomo III. P. 419-22. 1816 .

6.- Agricultura, Protomedicato, Panteón, Hospicio, Vacunas, Hospitales. Archivo Nacional. 1825-1840. 